\title{
La investigación en las facultades de educación
}

Luchamos ahora contra una dirección. Pero esta dirección morirá, eliminada por otras direcciones y entonces nadie entenderá nuestros argumentos en su contra; no comprenderá por qué hubo que decir todo eso.

L Wittgenstein

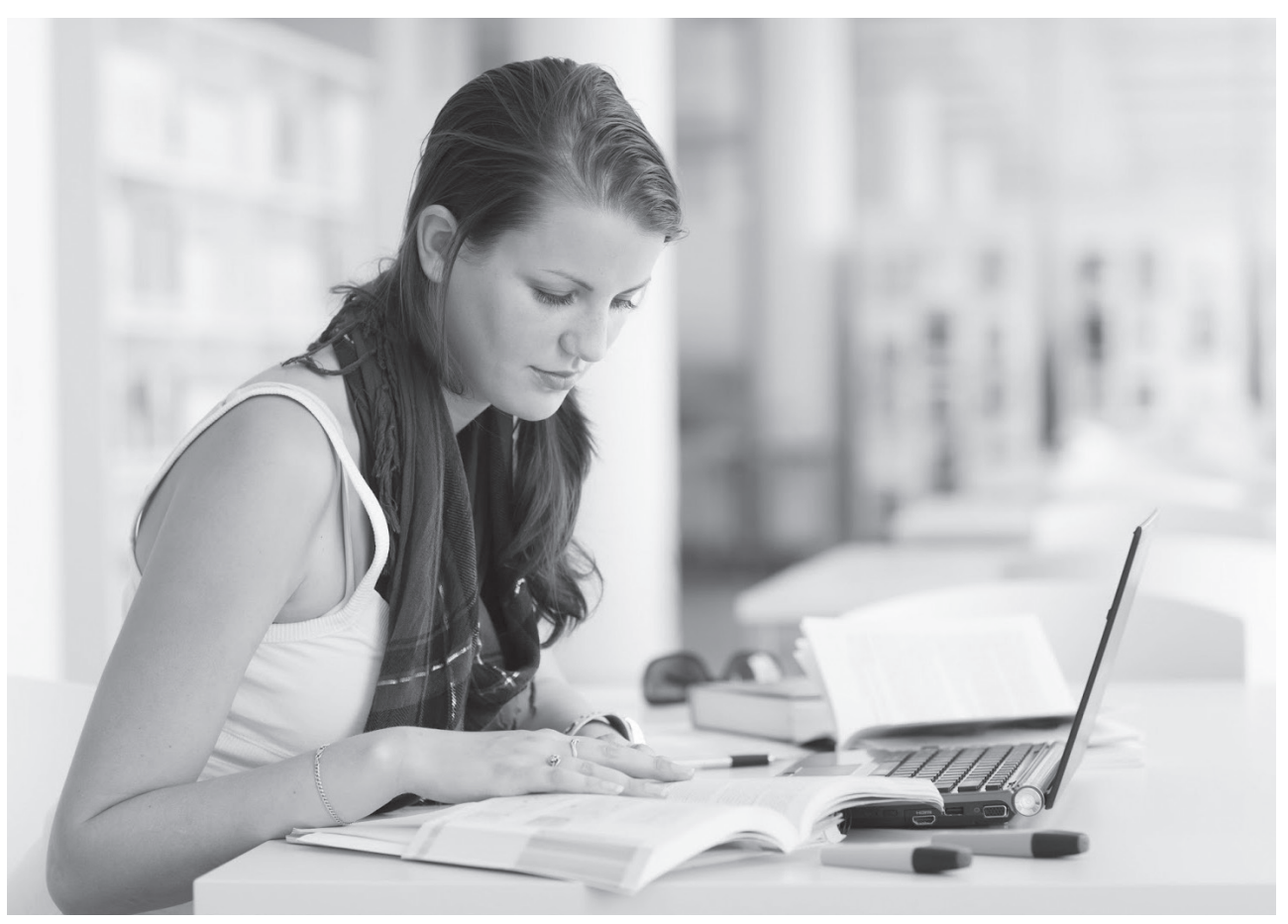

El lenguaje es mi mundo y mi mundo es mi lenguaje, es una caja de resonancia wittgenstaniana. Somos juegos del lenguaje, solo nos damos cuenta de ello a través del lenguaje. La investigación en la universidad colombiana, en particular el cúmulo de trabajo sobre la pregunta por una mejor educación, establece el substrato de la escuela como institución por excelencia como forjadora de imaginarios, de herramientas y de posibilidades para el mundo.

Entonces la exposición de los escenarios mundiales en este número 15 de la revista Papeles pretende contribuir al debate sobre el panorama, caminos y tendencias de vanguardia de la investigación en las facultades de educación y publicaciones afines. De un modo particular, se ha intentado rastrear la investigación desde las publicaciones especializadas, tanto a nivel nacional como internacional, con el fin de mostrar tendencias temáticas y enfoques de vanguardia. Esperamos contribuir con esto al debate y a las nuevas rutas de trabajo en las universidades del s. XXI. 
El quehacer académico en las facultades de educación anda en boga de autoridades gubernamentales, de las instituciones rectoras de la academia, de los padres de familia, entre otros agentes; pues la escuela es el espacio en su espectro amplio de gestación y debate del discurso moderno, del lenguaje escultor de la persona, del ser actual. El tema del valor agregado riguroso, desde el aula, pasando por los tejidos teóricos hasta el rigor de medición y valoración de los resultados se torna imperativo. La acción y la transformación sobre problemas concretos deben ocuparnos. Las dificultades ideológicas, institucionales, represivas, presupuestales, marginales, no pueden distraernos de debates disciplinarios, en los que el mismo discurso pedagógico se actualiza e irradia camino de la construcción social de la realidad, en aras de una mayor equidad, eficiencia y convivencia. El panorama actual ideológico, científico, social se presenta complejo para la academia en varias perspectivas. Los problemas de pertinencia, impacto y rentabilidad deben ser tomados en la cuenta a la hora de emprender proyectos de investigación.

Frente a los retos complejos de una modernidad inconclusa, de un mundo fragmentado en múltiples aspectos, confundida en sus razones para incluso cuestionar la Ilustración; el debate en las facultades de educación emerge como un arma de doble filo. De un lado, se corre el riesgo de que la escuela como institución social (en todos los niveles escolares), sea perpetuadora en el seno de su quehacer de las carencias tanto cognitivas, como disciplinares y emancipatorias (la apuesta debe integrar todas las dimensiones y posibilidades para ocupar un lugar digno en el mundo); o bien, la escuela asume el papel de construcción de un ser moderno, tan ilustrado como dialéctico y crítico, sin caer en los prejuicios de algunos científicos sociales, denunciados ya por Habermas, para quienes la tarea arqueológica para exponer y denunciar la estructura del poder, agota otras instancias como el desarrollo cognitivo mismo volcado en el espacio de construcción de universales sin absolutos, en diálogo permanente entre la voz y el mercado, entre la equidad y la eficiencia, entre el derecho y el deber; el debate por la equidad (un aspecto de la modernidad) no puede ocultar la construcción permanente del mundo moderno (racionalizado). Por el contrario, una modernidad rigurosa fortalece la lucha por la equidad. Fragmentar la construcción propicia una diferencia alienante atrapada en los gritos de libertad. La libertad ajena a la construcción de un lenguaje cohesivo con el otro, aliena y segrega, engendra la guerra. Los discursos falsamente libertarios siembran los pueblos de rencor y terminan en tejidos neoconservadores radicales, sin exclusas para un diálogo con mínimos consensuados.

Asumir este debate con responsabilidad social, política y económica; con la responsabilidad de la convivencia, de la equidad y de la eficiencia, va a determinar los retos de construir una verdadera sociedad moderna en Colombia.

Enrique Ferrer-Corredor 